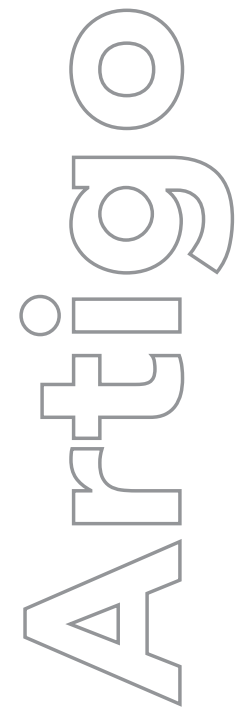

\section{revista}

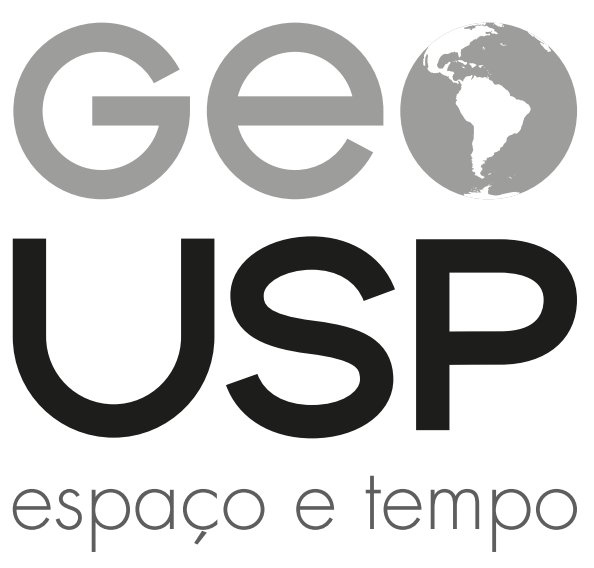

Volume $24 \cdot n^{\circ} 2(2020)$

ISSN 2179-0892

\title{
Uma cidade e três centros: o caso de Marabá (PA)
}

\section{Mauro Emilio Costa Silva}

Universidade do Estado do Pará, Castanhal, PA, Brasil e-mail: maurobrasilgeo@yahoo.com.br (1) 0000-0003-0260-0758

\section{p. $262-278$}

Como citar este artigo:

SILVA, M. E. C. Uma cidade e três centros: o caso de Marabá (PA). Geousp - Espaço e Tempo (On-line), v. 24, n. 2, p. 262-278, ago. 2020. ISSN 2179-0892.

Disponivel em: https://www.revistas.usp.br/geousp/article/ view/161465. doi: https://doi.org/10.11606/issn.2179-0892. geousp.2020.161465.

\section{(c) (i)}

Este artigo está licenciado sob a Creative Commons Attribution 4.0 Licence 


\section{Uma cidade e três centros: o caso de Marabá (PA)}

\section{Resumo}

Este artigo analisa, por meio da funcionalidade dos equipamentos urbanos e do uso do solo, o que confere a condição de três áreas centrais na cidade de Marabá-PA a Marabá Pioneira, a Nova Marabá e a Cidade Nova. A abordagem metodológica vale-se dos conceitos de centro e centralidade urbana. Ainda que possam gerar ambiguidades ou mesmo sugerir equivalência, esses dois elementos conceituais estruturadores da cidade não podem ser confundidos, pois a condição matricial do centro é a localização, enquanto a centralidade é condicionada pela variação. $O$ centro é sustentado pela centralidade, que é fugaz e móvel; pode abrigar-se em outra área que melhor o atenda, sobretudo num momento de globalização planetária, produzindo outra área central. Nesse caso, a égide do movimento é o fator econômico, seja de caráter moderno ou tradicional. Quanto à metodologia operacional, fizeram-se registros fotográficos e entrevistas semiestruturadas com 90 indivíduos em cada centro, e os resultados apontaram justamente três centros consolidados.

Palavras-chave: Marabá. Centro. Centralidade. Espaço. Intraurbano.

\section{A city and three centers: the case of Marabá (PA)}

\section{Abstract}

This paper aims to analyze by means of functionality of urban equipment and land use in three central areas of the city of Marabá-PA, namely Marabá Pioneira, Nova Marabá, and Cidade Nova. The analytical methodological approach was based on the concepts of urban center and centrality. These two urban Law Suit, center and centrality, may generate ambiguities or even equivalence as structuring conceptual elements of city, however they cannot be confused although they overlap. Center has locality as its matrix condition while centrality is conditioned by variation. Center is supported by centrality. Since centrality is fleeting and mobile it can be sheltered in another area that best suits it, especially at a time of planetary globalization, producing another central area. In this case, the aegis of movement is the economic factor, whether modern or traditional. As operational 
methodology, semi-structured photographic records and interviews were conducted with ninety individuals in each center. The results pointed for synthesis of three centers consolidated.

Keywords: Marabá. Center. Centrality. Space. Intra-urban.

\section{Una ciudad y tres centros: el caso de Marabá (PA)}

\section{Resumen}

El objetivo de este artigo es hacer un análisis por medio de la funcionalidad de los equipamientos urbanos y el uso del suelo, lo que confiere una condición a las tres áreas en la ciudad de Marabá-PA, cuyas las áreas son denominadas Marabá Pioneira, Nova Marabá y Cidade Nova. El abordaje metodológica analítica ocurrió por el medio de los conceptos de centro y centralidad urbana. Los dos processos urbanos, centro y centralidad, aún que no puedan generar ambigüedad o mismo equivalencia, cuanto elementos conceptuales estructurados de la ciudad, no pueden ser confundidos, mientras si sobrepongan, pues el centro tiene como condición matricial a localización mientras la centralidad es condicionada por la variación. El centro es sostenido por la centralidad, siendo esta, corta y móvil, puede abrigarse en otra área que mejor la atienda, especialmente, en un momento de globalización planetaria, produciendo otra área central. En este caso, la égida del movimiento es el factor económico sea de carácter moderno, sea tradicional. Cuanto la metodología operacional, fue realizado registros fotográficos y entrevistas semiestructuradas con noventa individuo en cada uno de los centros, cuyos los conocimientos apuntan para la síntesis de las tres centros consolidados.

Palabras clave: Marabá. Centro. Centralidad. Espacio. Intraurbano. 


\section{Introdução}

Quando se analisam aspectos antigos da cidade e do urbanismo, é comum recorrer aos conceitos da Escola de Chicago. ' Contudo, cumpre salientar que os autores dessa escola partem de premissas da Sociologia Urbana, cuja contribuição para a Geografia são principalmente seus recursos teórico-metodológicos, ou as referências empíricas. Sendo a morfologia das cidades brasileiras muito diferente da das estadunidenses, há limites para a adoção conceitual de suas acepções tempo-espaciais.

Tais métodos de investigação na pesquisa social eram novidade para os anos 1910, especialmente nas cidades estadunidenses que vivenciavam processos de urbanização e seus corolários socioespaciais regionais específicos. Entretanto, é inegável o legado da Escola de Chicago para alguns temas da Geografia Urbana, como área central, centralização/descentralização, segregação e invasão/sucessão, que viriam a suscitar pesquisas futuras acerca da dinâmica da cidades tais como os centros urbanos.

Aqui não se discutem ou mencionam todas as ideias e os autores da Escola de Chicago, mas apenas os que auxiliam o presente ensaio, discernindo os postulados que se aproximam do objeto da pesquisa (não consistindo numa correlação exata entre as áreas centrais das cidades estadunidenses e Marabá) e trazem elementos que podem nortear os processos que cercam a centralidade urbana ${ }^{2}$ dos três centros marabaenses.

Sabe-se que nessa escola há uma forte comparação entre os seres da comunidade biótica como explicação da dinâmica existente entre os homens e a cidade, estabelecendo uma abordagem teórica: a Ecologia Humana ou Urbana. Ainda que se apresentem limitações na analogia, não é nossa proposta evidenciar, mas desvelar compreensões válidas, especialmente quanto às externalidades positivas ${ }^{3}$ e à produção do centro comercial.

Na realidade brasileira, Corrêa (1989) denominou área que concerne aos arredores do centro comercial Zona Periférica do Centro. Em ambas as proposições (estadunidense e brasileira), essa denominação tem a mesma conotação: áreas que perderam a função inicial como comércio ou indústria, tornando-se depósito de mercadorias, habitações de baixo padrão, garagens e mesmo subutilizadas.

Quanto aos fatores responsáveis pela formação do centro e sua descentralização, adotou-se aqui a perspectiva da Escola de Chicago, que enfatizou o centro e suas derivações decorrentes de sua evolução, embora houvesse postulações européias contemporâneas com uma morfologia diferente.

A cidade é em seu espectro, movimento, sobretudo a capitalista, cujo centro e as dinâmicas de centralidade carregam a celeridade das transformações do conteúdo urbano trazido ou gerado pelos eventos econômicos, sociais e culturais, sendo um corolário que se apresenta de base empírica, exigente de substanciais teóricos para um maior aprofundamento.

\footnotetext{
1 "[...] uma das mais importantes contribuições dos sociólogos de Chicago foi o desenvolvimento de métodos originais de investigação, que iam desde a utilização de documentos pessoais, passando por trabalhos sistemáticos de campo e chegando à exploração de diferentes fontes documentais" (Teodósio, 2003, p. 4).

2 "A centralidade urbana pode ser abordada em duas escalas territoriais: a intraurbana e a rede urbana. No primeiro nível, é possível enfocar as diferentes formas de expressão dessa centralidade tomando como referência o território da cidade ou da aglomeração urbana, a partir de seu centro ou centros" (Spósito, 1997, p. 27).

3 São as relações que concorrem para o crescimento do centro urbano.
} 


\section{Centro: elementos teórico-conceituais}

centro da cidade em uma dimensão analítica temporal é anterior ao capitalismo, entre as quais, as cidades portuárias e comerciais (Spósito, 2008), como também é possível aludir que o centro coincide com o desenvolvimento das cidades capitalistas, como um atestado da sua originalidade representado nas paisagens que mediam o processo espacial. Em tese de doutoramento, intitulada O centro da cidade do Salvador, Santos (2012) discutiu o centro urbano.

Sendo um dos estudos seminais brasileiros relativos à dimensão geográfica interpretativa do centro, cuja inferência demonstrou "o centro constitui uma verdadeira síntese, pois reflete, ao mesmo tempo, as formas atuais da vida da região e da cidade e o passado, seja pela evolução histórica" (Santos, 2012, p. 28).

A tese mencionada tornou-se uma proposta metodológica para o estudo do centro ao pesquisar: (1) o sentido e o ritmo da evolução da região e da cidade, (2) os dados do sítio e (3) as formas atuais da organização e da vida urbana, incluindo, de um lado, o dinamismo atual (força de transformação), e, de outro lado, as forças de inércia (Santos, 2012, p. 29). Esse intento foi considerado um salto qualitativo, pois as geografias mundial e brasileira se encontravam no início da renovação, divorciando-se de suas bases positivistas.

Em uma conceituação mais recente, Spósito (2017, p. 28) anuncia que "O centro constitui-se por meio de um processo de concentração de atividades de comercialização de bens e serviços, de gestão pública e privada, de lazer e de valores materiais e simbólicos em uma área da cidade".

A perspectiva de empreender a análise da cidade pela ótica do centro é fortalecida pelos princípios da aglomeração urbana ${ }^{4}$ e da concentração espacial. ${ }^{5}$ Embora esses princípios estejam imersos em conteúdos sociais e formas novas, os resíduos espaciais antigos não desaparecem completamente, sendo o centro um representante socioespacial.

No que tange ao conceito de centro principal e tradicional, "[...] tratar-se de duas possibilidades analíticas e não de dois centros, necessariamente, devemos compreender que suas funções e papéis não são os mesmos. $\bigcirc$ 'tradicional' e o 'principal' são, assim, e novamente, relacionais e relativos" (Whitacker, 2012, p. 292).

No intuito de operacionalizar tais adjetivações, o centro tradicional remeteria à mesma fração do principal que, em alguns casos, ${ }^{6}$ podem não estar atrelados, já que o primeiro guarda as relações pretéritas da cidade e o segundo se deve à maior densidade de objetos espaciais de cunho comercial.

Ainda que o centro principal compartilhe nodosidade de complementariedade com outras áreas centrais da cidade, em ambos, há "relações objetivas e subjetivas" (Salgueiro, 2012). Assim sendo, existem nuances comuns entre os centros de uma mesma cidade e mesmo entre centros de cidades de níveis diferentes.

4 Para Miyazaki (2017), a junção ou concentração de pessoas, construção, serviços, comércio, indústria etc. num centro urbano já caracterizaria uma aglomeração, ou seja, a cidade compreendida como um aglomerado urbano.

5 Em Marx (1996), o conceito de concentração está atrelado à acumulação. Numa tentativa de inserir o capital social na discussão geográfica, o conceito precisou da dimensão espacial e, por conseguinte, do princípio de localização que necessariamente implica a distinção de áreas figurando o centro. Para um aprofundamento da discussão, ver Smith (1988).

6 No caso de Marabá, é coerente falar em tradicional e principal da mesma fração espacial. 
Sobre apropriação funcional e simbólica comum do(s) centro(s) como características próprias desses espaços, eis algumas noções duais e articuladas: aglomeração-dispersão (diário/ noturno), capital-trabalho, aleatório-burocrático, negócio-lúdico, sociabilidade-individualidade, antigo-moderno, endogenia-exogenia, rapidez-lentidão, afetividade-inafetividade, formal-informal, gestão-reivindicação, seguro-inseguro, encontro-desencontro, variável-invariável, organização-entropia, engodo-elucidação, razão-emoção, visível-invisível e vazio-cheio.

O centro é o espaço-tempo por excelência da fluidez complexa condizente ao nível hierárquico da cidade e à necessidade de circulação de capital. Em outros termos, o(s) centro(s) é(são) diretamente proporcional(is) à dinâmica econômica da cidade, não excluindo as dimensões culturais, históricas e políticas.

O processo de produção espacial em outras frações da cidade com características de centro tem seu surgimento associado ao crescimento da cidade, processo denominado descentralização ${ }^{7}$ em forma de núcleos secundários.

A descentralização com a criação de núcleos ${ }^{8}$ secundários, que no caso, marabaense a perspectiva é, complementariedade entre si expressa uma complexificação do tecido urbano, na medida em que revela outras possibilidades de reprodução do conteúdo do centro principal, para além do extrato social a que se destine. Há uma forma que se desenha na cidade que repercute não apenas na paisagem intraurbana como nas suas relações horizontais e verticais, tendo em vista que esses rearranjos espaciais incidem na mudança da prática espacial, processo mais fortemente percebido nas periferias.

\section{Centralidade: elementos teórico-conceituais}

Impõe-se que o tecido urbano de Marabá esteja caminhando para uma estruturação poli nucleada, processo que Villaça (2001) admite ter origens nas metrópoles estadunidenses com a reprodução dos centros urbanos em consonância com a necessidade de reprodução capitalista. Embora Marabá seja uma cidade média, sua condição do sítio urbano9 se combinou com a prevalência do dinamismo econômico produzindo a polinucleação engendrada pelo binômio centro-centralidade. Essa condição se justifica, em parte, pelo patamar demográfico, um dos maiores depois da capital do estado, Belém.

7 A descentralização verificada em áreas não centrais, com as seguintes características: (a) terras não ocupadas, a baixos preços e impostos, (b) infraestrutura implantada, (c) facilidade de transporte, (d) qualidades atrativas do sítio como topografia e drenagem, (e) possibilidades de controle do uso da terra e (f) amenidades (Corrêa, 1989, p. 4).

8 núcleo em referência abrange uma porção de função residencial e comercial da cidade, porém aqui será analisada apenas a segunda função em sua circunscrição de centro.

9 Ab'Saber (1957, p. 112) considera o sítio urbano como "um pequeno quadro de relevo que efetivamente aloja um organismo urbano". 
Quadro 1 - População absoluta de municípios do estado do Pará

\begin{tabular}{|c|c|c|c|c|c|c|c|}
\hline $\begin{array}{l}\text { Código do } \\
\text { município }\end{array}$ & $\begin{array}{l}\text { Nome do } \\
\text { município }\end{array}$ & $\begin{array}{c}\text { Total da } \\
\text { população } \\
2000\end{array}$ & $\begin{array}{l}\text { Total de } \\
\text { homens }\end{array}$ & $\begin{array}{l}\text { Total de } \\
\text { mulheres }\end{array}$ & $\begin{array}{c}\text { Total da } \\
\text { população } \\
\text { urbana }\end{array}$ & $\begin{array}{c}\text { Total da } \\
\text { população } \\
\text { rural }\end{array}$ & $\begin{array}{c}\text { Total da } \\
\text { população } \\
2010\end{array}$ \\
\hline 1500107 & Abaetetuba & 119.152 & 71.612 & 69.442 & 82.950 & 58.104 & 141.054 \\
\hline 1500131 & $\begin{array}{c}\text { Abel } \\
\text { Figueiredo }\end{array}$ & 5.957 & 3.542 & 3.250 & 6.046 & 746 & 6.792 \\
\hline 1500206 & Acará & 52.126 & 28.139 & 25.466 & 12.625 & 40.980 & 53.605 \\
\hline 1500305 & Afuá & 29.505 & 18.449 & 16.568 & 9.478 & 25.539 & 35.017 \\
\hline 1500347 & $\begin{array}{l}\text { Água Azul } \\
\text { do Norte }\end{array}$ & 22.084 & 13.618 & 11.443 & 4.876 & 20.185 & 25.061 \\
\hline 1500404 & Alenquer & 41.784 & 27.086 & 25.628 & 27.774 & 24.940 & 52.714 \\
\hline 1500503 & Almeirim & 33.957 & 17.502 & 16.163 & 19.972 & 13.693 & 33.665 \\
\hline 1500602 & Altamira & 77.439 & 52.814 & 52.216 & 90.068 & 14.962 & 105.030 \\
\hline 1500701 & Anajás & 18.322 & 12.968 & 11.803 & 9.492 & 15.279 & 24.771 \\
\hline 1500800 & Ananindeua & 393.569 & 226.537 & 245.207 & 470.590 & 1.154 & 471.744 \\
\hline 1500859 & Anapu & 9.407 & 10.965 & 9.528 & 9.840 & 10.653 & 20.493 \\
\hline 1500909 & $\begin{array}{l}\text { Augusto } \\
\text { Corrêa }\end{array}$ & 33.011 & 20.994 & 19.505 & 18.237 & 22.262 & 40.499 \\
\hline 1500958 & $\begin{array}{c}\text { Aurora do } \\
\text { Pará }\end{array}$ & 19.728 & 13.630 & 12.949 & 8.174 & 18.405 & 26.579 \\
\hline 1501006 & Aveiro & 15.518 & 8.319 & 7.448 & 3.182 & 12.585 & 15.767 \\
\hline 1501105 & Bagre & 13.708 & 12.136 & 11.719 & 10.652 & 13.203 & 23.855 \\
\hline 1501204 & Baião & 21.119 & 19.450 & 17.457 & 18.555 & 18.352 & 36.907 \\
\hline 1501253 & Bannach & 3.780 & 1.849 & 1.585 & 1.284 & 2.150 & 3.434 \\
\hline 1501303 & Barcarena & 63.268 & 50.379 & 49.421 & 36.357 & 63.443 & 99.800 \\
\hline 1501402 & Belém & 1.280 .614 & 658.188 & 733.843 & 1.380 .836 & 11.195 & 1.392 .031 \\
\hline 1504208 & Marabá & 168.020 & 118.148 & 115.314 & 186.122 & 47.340 & 233.462 \\
\hline
\end{tabular}

fonte: IBGE ([s.d.]).

A centralização ${ }^{10}$ do capital é uma condição para a constituição da centralidade do espaço, torna-se necessária a emersão analítica da escala para que se possa "ler" a ação dos agentes produtores da centralidade, haja vista que estes agentes nem sempre são locais, porém a materialidade do capital é localizada e se expressa objetivamente com domínios pontuais na vida urbana.

A importância de incorporar a escala geográfica consiste não apenas em situar o objeto pesquisado, mas atribuí-lhe potencialidade. Concorda-se que o centro e a centralidade exercem um papel precípuo na escala da cidade, no tocante a nodosidade das conexões "horizontais e verticais" (Santos, 2008).

10 "A centralização do capital ocorre quando dois ou mais capitais antes independentes se combinam num único, e isso geralmente ocorre diretamente através de uma incorporação ou encampação, ou indiretamente através do sistema de crédito" (Smith, 1988, p. 178). 
Assim, a identificação de seus potenciais de viabilização dos fluxos econômicos horizontais e verticais dimensiona e qualifica os eventos presentes como vetores de prováveis rearranjos socioespaciais.

Baseando-se na teoria geográfica das inserções de fenômenos espaciais como eventos sempre singulares nos diversos lugares, ainda que possam ser solidários, pressupõe-se que o evento é um "dado do tempo no espaço" (Santos, 2008) e um "momento" (Lefebvre, 1991). Ambos concordam que o evento é um fenômeno irreversível e muda a história do lugar.

A abrangência do nível escalar da cidade por meio da centralidade é dimensionada de acordo com o grau de polarização e influência que o evento pode alcançar. Nesse caso, para a pesquisa, a escala concerne ao nível intraurbano nos termos "localidades centrais intraurbanas" (Souza, 2013), não desconsiderando que sua influência pode extrapolar para o nível interurbano.

A centralidade como um processo espacial de cunho econômico é predominantemente abordada no nível interurbano, na rede urbana, mesmo nacional e global; para Lefebvre (1999), "a centralidade é o essencial do fenômeno urbano".

No nível da cidade, a centralidade, a partir de seu centro ou centros, para Spósito (1997) "é ativada pelas atividades de comércio e serviços", a princípio, de modo multivetorial, isto é, por meio da ação de vários agentes de segmentos diferentes.

Por via de regra, na escala intraurbana, as frações espaciais destinadas à centralidade econômica constituem-se essencialmente de dois fatores sequenciais: a modernização como "acréscimo de ciência e técnica no espaço" (Santos; Silveira, 2014) e a acessibilidade. Esses fatores são elementos reestruturadores do espaço que expressam a paisagem urbana funcional da cidade atual. Nesse sentido, para Camagni (2005, p. 74), "accesibilidad significa superar la barrera impuesta por el espacio al movimiento de personas y cosas y al intercambio de bienes, servicios e informaciones".

Nas áreas tidas na condição de centralidade comumente predomina a modernização agregada à superfície de serviços e comércio que se destinam à troca, reapresentada na paisagem urbana e inserida nas estratégias mercadológicas de massificação do produto e do lugar (como, por exemplo, os shopping centers). Para tanto, o acesso a essas áreas deve ser tal que ruas, avenidas, trilhos etc. a conectem com a maior parte possível da cidade.

\section{De Marabá aos três núcleos urbanos para seus centros}

O município de Marabá está situado na região Norte, na Amazônia brasileira, na mesorregião do sudeste do estado do Pará, à margem esquerda do rio Tocantins. Com uma altitude média de 125 m em relação ao nível do mar, tem uma área de $15.157,90$ km², e sua população é de 233.462 habitantes. Faz limite, ao norte, com os municípios de Itupiranga, Nova Ipixuna e Rondon do Pará; ao sul, com Parauapebas, Eldorado dos Carajás e São Geraldo do Araguaia; a leste, com São Domingos do Araguaia, São João do Araguaia e Bom Jesus do Tocantins e, a oeste, com o município de Novo Repartimento (IBGE, [s.d.]). 


\section{Mapa 1 - Situação geográfica de Marabá no estado}

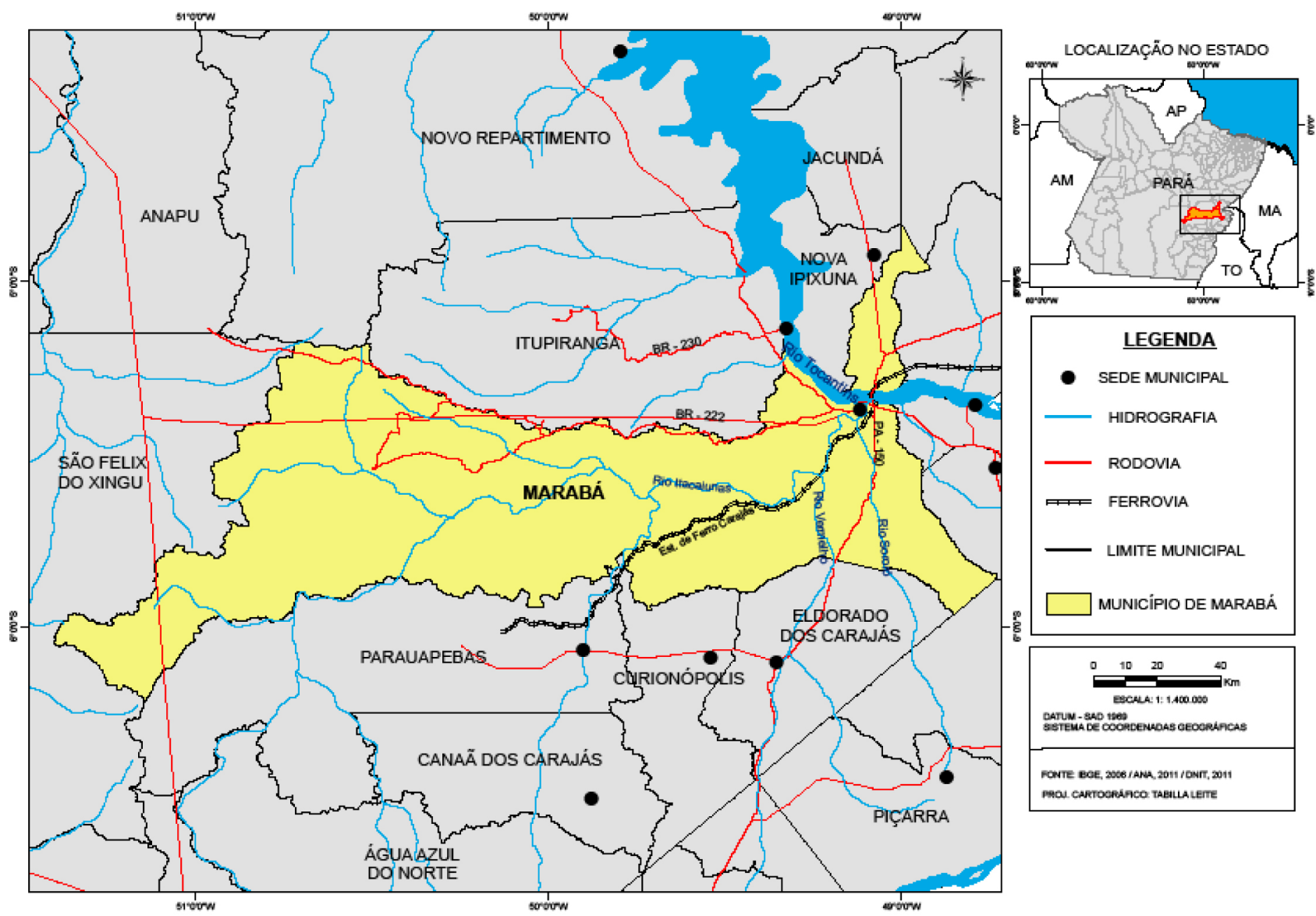

fonte: IBGE ([s.d.]).

elaboração: Mauro Emilio, 2015.

comentário: A maior parte dos municípios que hoje fazem limite com Marabá são oriundos de seu desmembramento.

As principais transformações urbanas da cidade são as induzidas por atividades capitalistas de alto investimento. Dessa maneira, a atividade mineradora desempenhou esse papel na região do sudeste do Pará a partir de 1970, elegendo a cidade de Marabá como suporte espacial do capital e do próprio estado, incluindo a presença dos migrantes.

A inserção de atividades econômicas extralocais reconfigura a localização intraurbana dos objetos espaciais, no caso de Marabá, numa perspectiva de surgimento de centros e centralidades, cuja configuração em três porções distintas na cidade já se observara: "Desde a década de 1980 já apresentava uma estrutura intraurbana tripartide, diferenciada a saber: (a) a Marabá Pioneira, comércio mais tradicional, (b) a Nova Marabá, planejada pela Sudam, (c) a Cidade Nova, resultado da ocupação mais espontânea" (Becker, 1990, p. 56).

A percepção da autora citada tem um valor essencial para a compreensão do surgimento e da caracterização espacial dos três centros. Contudo, a celeridade do movimento urbano e econômico tende a se afastar de seus processos precursores de formação não com rupturas abruptas, mas com o movimento dialético de mudanças-permanências mais ou menos intensas em cada uma, cuja expressão espacial de análise se desdobra socioespacialmente. 


\section{Centro e centralidade dos/nos núcleos: Marabá Pioneira, Nova Marabá e Cidade Nova}

A situação geográfica dos três núcleos no sítio urbano marabaense se expressa em sua descontinuidade espacial, permitindo vislumbrar no centro de cada núcleo uma relativa dependência amparada numa relação de solidariedade organizacional intraurbana por meio das atividades de serviços e comércio, dando uma característica particular à produção espacial marabaense e sendo também uma possível racionalidade específica entre os agentes econômicos alocados nas três áreas.

O uso do solo urbano de Marabá vem sofrendo um processo de instalação de atividades econômicas em que serviços e comércio ganham destaque por representar uma parte considerável desse uso associado à expansão urbana da cidade.

A apreciação do uso do solo urbano pode ser verificada no Mapa 2.

\section{Mapa 2 - Setores de uso do solo urbano de Marabá}

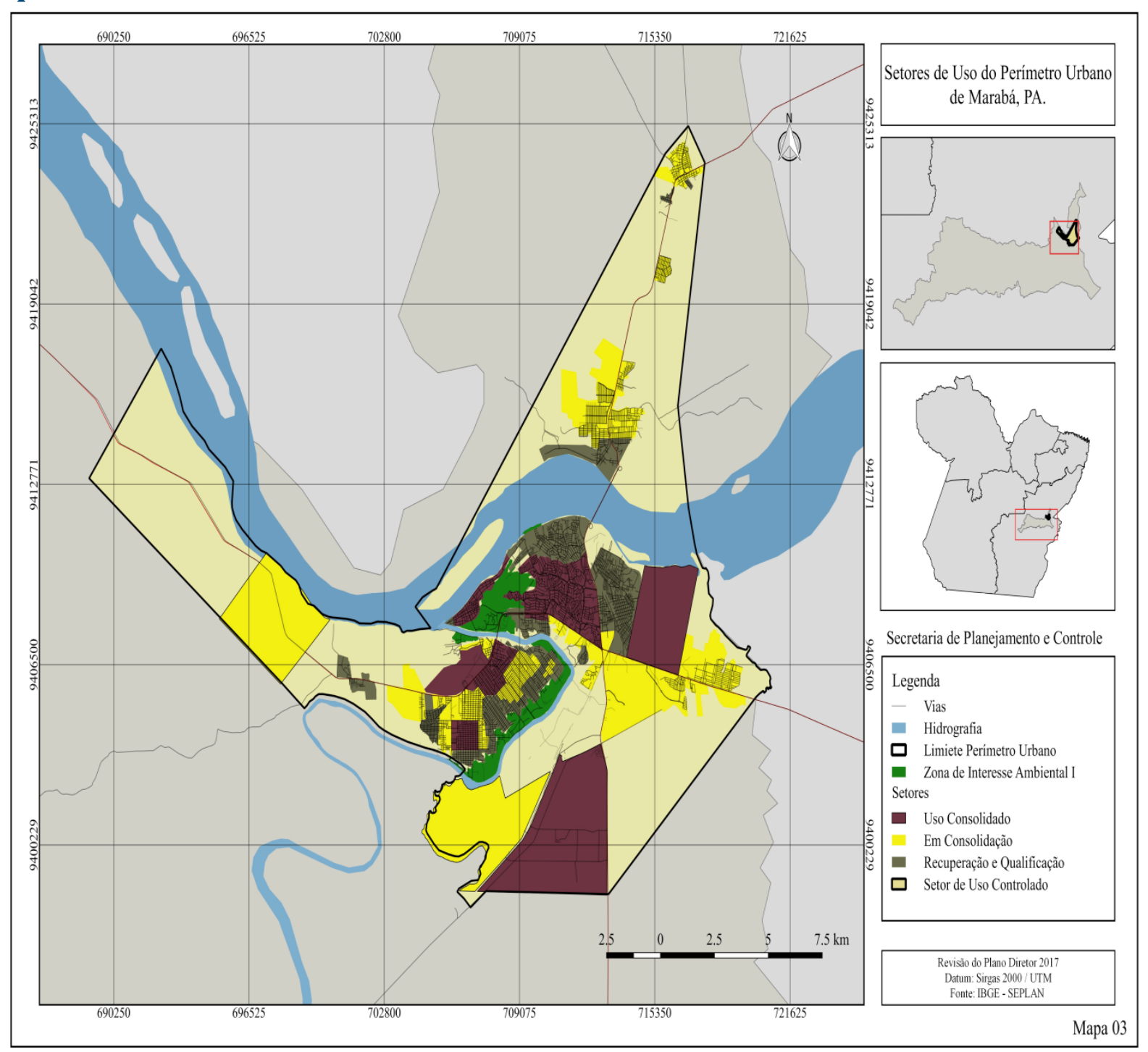

fonte: Marabá ([s.d.]).

Com o georreferenciamento dos setores quanto ao uso do solo, é possível perceber que as áreas de uso consolidado e em consolidação estão situadas nas subáreas concernentes aos 
três núcleos que incluem seus respectivos centros, possibilitando aludir as atividades de serviços e comércio como vetores deste processo de solidificação de uso do solo.

\section{Marabá Pioneira}

$\bigcirc$ centro tradicional com suas vias de acesso e circulação de pessoas e veículos, lojas (vestuário, bijuterias, eletrodomésticos, eletrônicos), farmácias, óticas etc., configura um centro principal. As trocas permitem pensar numa relação interescalar (local, regional, nacional e global), por meio da ação de agentes econômicos de pequeno, médio e grande porte, que conseguem capturar, para este espaço, lógicas extralocais, produzindo verticalidades na medida em que se aprofundam novos comportamentos e consumos.

Quanto à centralidade de cunho tradicional, a Marabá Pioneira se destaca pela intensa atividade informal, com ênfase na transferência da feira Getúlio Vargas para uma área coberta, recentemente inaugurada em 5 de abril de 2018 (trabalho de campo).

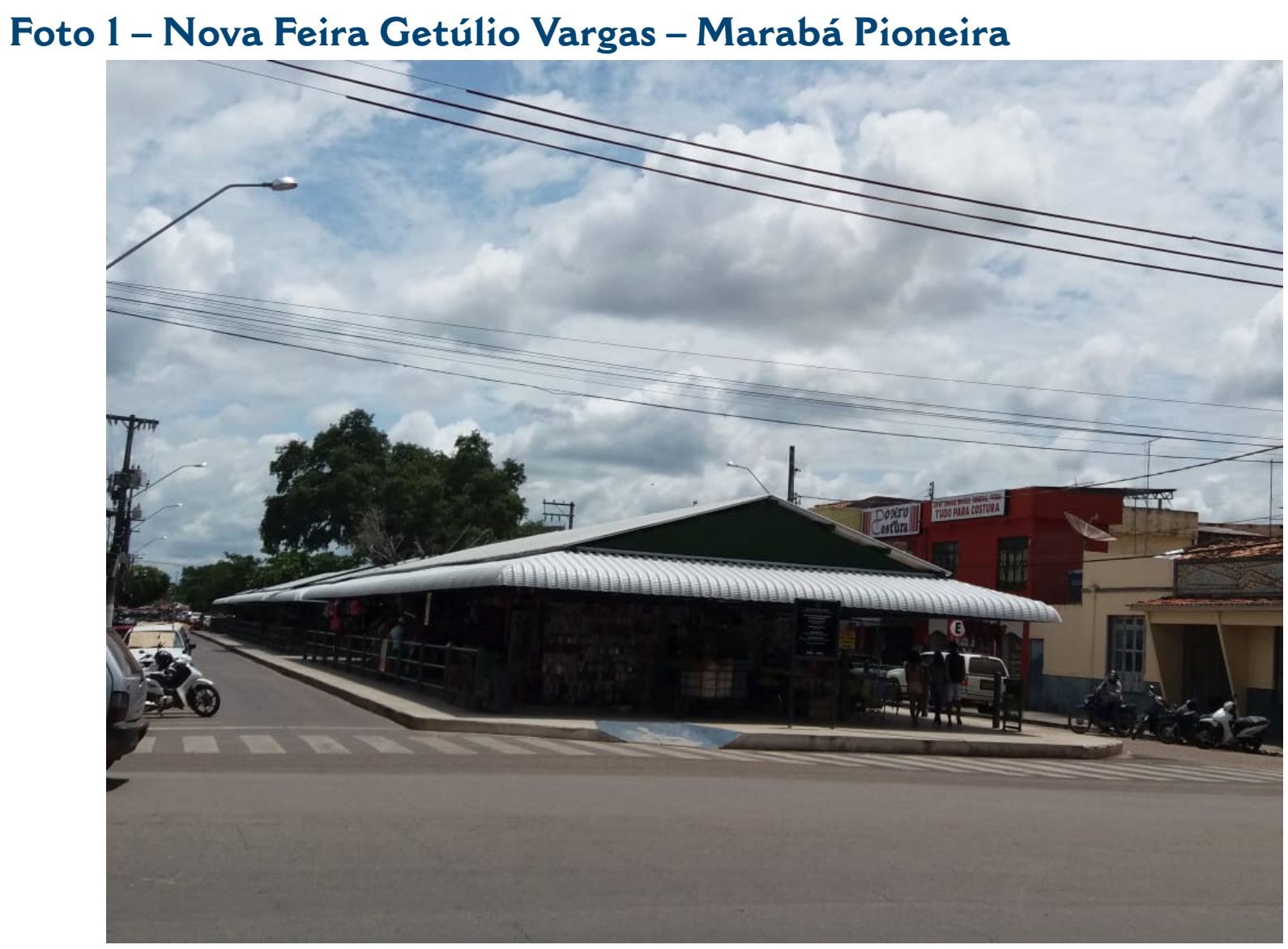

fonte: Trabalho de campo, julho de 2018.

A transferência para o novo espaço regulamentou os quiosques por tipologia de atividades entre vendas de eletroeletrônicos, roupas, calçados, mídias sonoras e a parte destinada a alimentação com barracas padronizadas. Dessa maneira, emerge na área do centro uma perspectiva de centralidade tradicional informal não só pela ausência de um ambiente moderno, como também pelos resíduos de conteúdo social de tempos pretéritos em Marabá. Assim sendo, o referido centro é, ao mesmo tempo, tradicional e principal. 


\section{Nova Marabá}

A área central se vincula ao processo de "descentralização espacial" (Corrêa, 1989), mas ele aponta a perspectiva dual de que essas novas áreas se desenvolverão com uma complementariedade ou concorrência em relação ao centro principal? Essa pergunta permeia a dinâmica espacial das cidades brasileiras que vêm sofrendo redefinições no tecido urbano, decorrentes da intensidade das intervenções econômicas como fio condutor das remodelagens urbanísticas intraurbanas.

Para Yoschioka (1986), a produção espacial da Nova Marabá resultou da intervenção pública para redefinir o papel de Marabá no cenário político-econômico brasileiro nas décadas de 1970 e 1980, quando a mineração despontou no sudeste do Pará. Argumenta Tourinho (2011, p. 123) "[...] tinha como função estratégica abrigar contingentes populacionais advindos de Marabá Pioneira, bem como para servir de espaço de contenção para fluxos migratórios que se deslocavam para a sub-região sudeste do estado do Pará".

O principal equipamento urbano com rigor de centralidade econômica interescalar (horizontal e vertical), quanto à superfície de serviços e comércio do/no núcleo da Nova Marabá, é a presença do shopping center Pátio Marabá, criado em 2013. O empreendimento denota a perspectiva do processo da centralidade.

A presença de um equipamento urbano de serviços e comércio com traço capitalista moderno na escala da cidade, shopping center, cria per se um mosaico de perspectivas na vida urbana, cuja natureza é estandardizada, o que tende a uniformizar os comportamentos sociais.

\section{Foto 2 - Shopping center Pátio Marabá, situado na rodovia Transamazônica - Nova Marabá}

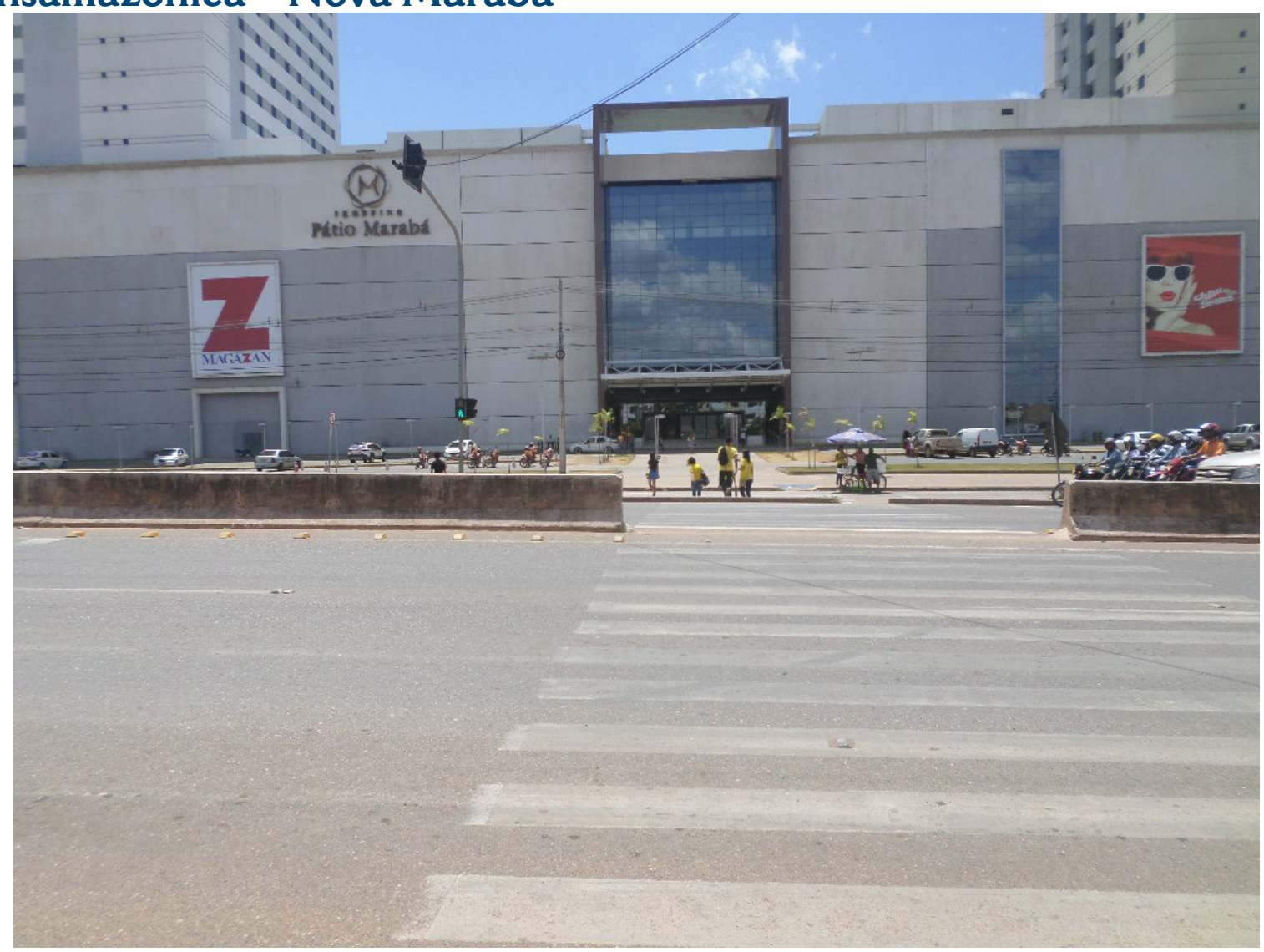

fonte: Trabalho de campo, março de 2016. 
Nota-se a intenção de estabelecer relações escalares em Marabá, especificamente na área central da Nova Marabá, por meio do shopping center Pátio Marabá, com franquias fast food e seus níveis de atuação espacial.

\section{Quadro 1 - Franquias fast food instaladas no shopping center Pátio Marabá - Nova Marabá}

\begin{tabular}{|l|l|l|}
\hline $\mathbf{n .}$ & franquia & escala \\
\hline 1 & Bebelu & nacional \\
\hline 2 & Jin Jin & nacional \\
\hline 3 & Bob's & nacional \\
\hline 4 & Pop Pastel & local \\
\hline 5 & Todde's & local \\
\hline 6 & Camarão E Cia & nacional \\
\hline 7 & Subway & global \\
\hline 8 & Parmeggio & nacional \\
\hline 9 & Haru Oriental food & nacional \\
\hline 10 & Patroni-Pizza & nacional \\
\hline 11 & Giraffa's & nacional \\
\hline 12 & Spoleto & nacional \\
\hline 13 & Lug's & nacional \\
\hline 14 & Ice Bode & regional \\
\hline 15 & Big x picanha & nacional \\
\hline
\end{tabular}

fonte: Trabalho de campo, julho de 2018.

elaboração: Mauro Emilio, 2019.

Entre as franquias presentes no shopping center Pátio Marabá, apenas duas têm origem local e uma regional, com 11 nacional e uma global. A dimensão de atuação escalar demonstra as articulações que a cidade de Marabá passa a exercer com a chegada do empreendimento, por meio do comércio realizado pelas franquias, além da cristalização do fenômeno da centralidade no conteúdo da área central do núcleo da Nova Marabá.

Na perspectiva da "cidade-região" (Lencione, 2017), isto é, de uma cidade que não é importante apenas para si, mas também para seu entorno regional, no qual está inserida com polarização transcendente de suas fronteiras, Marabá está na rede urbana sub-regional do sudeste paraense. Tal perspectiva enseja a "cidade neoliberal" (Massey, 2008), onde o capital privado nacional e internacional produzem formas e suscitam reestruturação urbana e da cidade.

\section{Cidade Nova}

O surgimento do núcleo Cidade Nova como um todo incluindo o centro, é considerado um produto da expansão urbana desordenada e ordenada de Marabá. "[...] diante do fracasso da política de colonização oficial empreendida pelo governo federal via Incra [Instituto Nacional 
de Colonização e Reforma Agrária], ao longo da rodovia Transamazônica, na sub-região sudeste paraense" (Tourinho, 2011, p. 123).

$\bigcirc$ núcleo também tem suas origens atreladas às constantes enchentes que assolavam a Marabá Pioneira, tornando-se um abrigo para as vítimas das enchentes; juntamente com os migrantes atraídos para a região por várias frentes de trabalho.

A produção social do espaço cria ambivalência entre áreas consideradas de "funcionalidades e disfuncionalidades para o capitalismo" (Gottdiener, 2010). As últimas, com poucas funções de troca do solo, são áreas que se destinam especialmente à habitação das classes trabalhadoras. Tal pressuposto teórico se aproxima do processo geo-histórico do núcleo da Cidade Nova.

Na Foto 3, há uma imagem do centro, com a acumulação de atividades de comércio e serviços, atribuindo-lhe a qualificação de centro de cidade juntamente com as duas outras (Marabá Pioneira e Nova Marabá), o que permite ampliar a ideia de multinuclealidade pela disposição de núcleos urbanos subordinados por um único centro para multinuclealidade com três centros polares na cidade de Marabá.

\section{Foto 3 - Área central da Cidade Nova, na esquina da avenida Nagib Mutran com a rua Frei Raimundo}

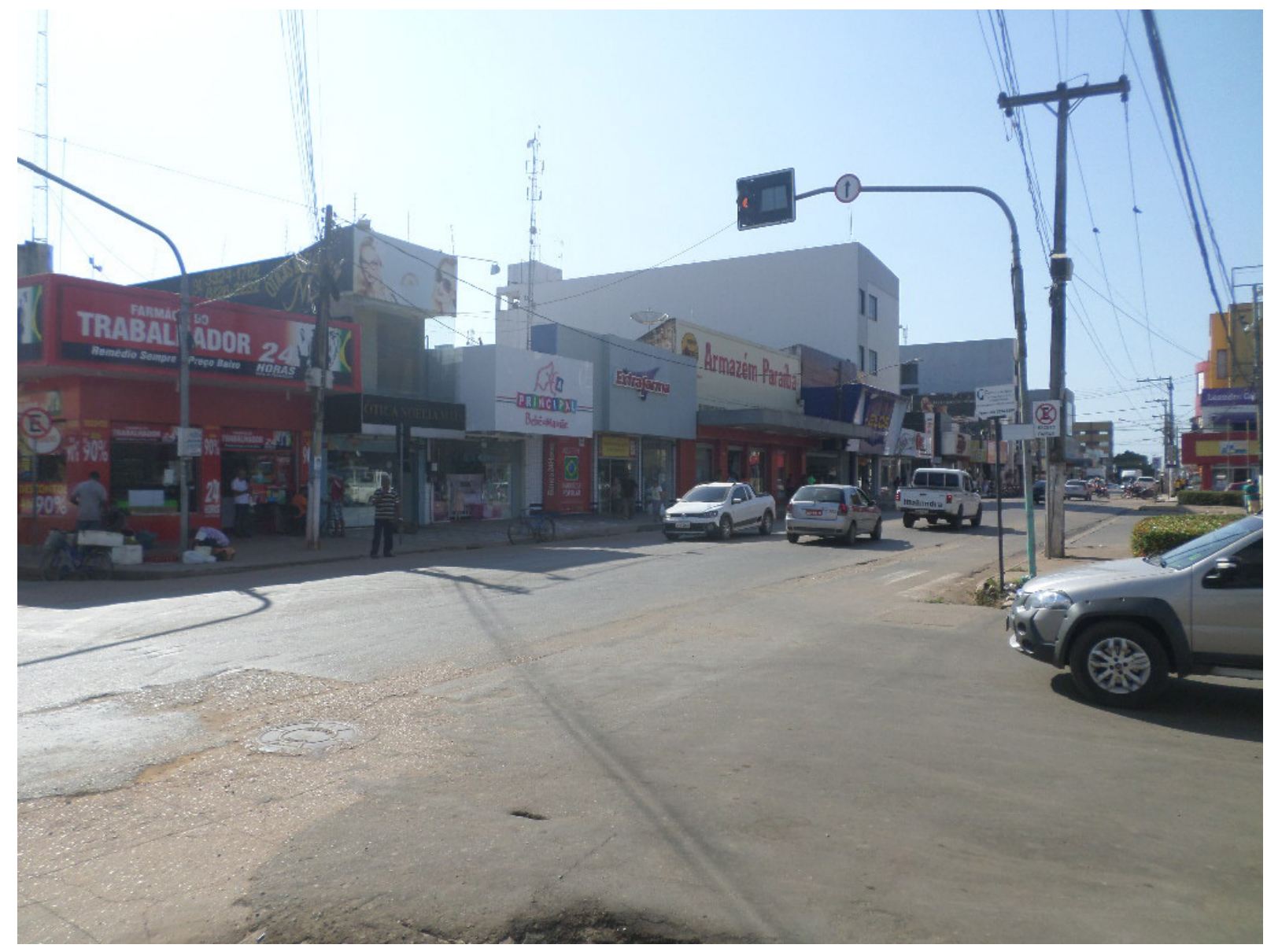

fonte: Trabalho de campo, março de 2016.

À medida que se se afasta da aglomeração da área central, percebem-se atividades econômicas menos complexas como, por exemplo, borracharias, oficinas, academias, restaurantes 
populares, hotéis de baixo padrão etc., teorizadas de "circuito inferior da economia urbana" 11 (Santos, 2004).

Outro critério útil como aporte teórico desse circuito é o pesquisado por Montenegro (2006), que distingue o número de trabalhadores no setor informal, aquele que emprega até dez pessoas numa dada atividade, sendo uma condição que aponta a demanda de serviços de baixa envergadura justificada pelo labor humano quantitativo.

No entorno imediato do centro, existe uma particularidade, a saber: entre os três centros, a Cidade Nova é o único que tem vida noturna com entretenimento infantil, bares e restaurantes de médio e alto padrão.

\section{Síntese dos três centros}

Para entender suas particularidades, foi essencial na pesquisa a interlocução com os sujeitos frequentadores dos centros.

\section{Quadro 2 - Questionário sobre o perfil socioeconômico dos frequentadores do centro}

\begin{tabular}{|c|c|c|c|}
\hline $\begin{array}{l}\text { núcleo/ } \\
\text { centro }\end{array}$ & centro Nova Marabá & centro Cidade Nova & $\begin{array}{c}\text { centro Marabá } \\
\text { Pioneira }\end{array}$ \\
\hline $\begin{array}{l}\text { tipo de } \\
\text { transporte } \\
\text { utilizado }\end{array}$ & $\begin{array}{l}35,7 \% \text { motocicleta } \\
7,1 \% \text { carro } \\
17,8 \% \text { bicicleta } \\
7,1 \% \text { coletivo } \\
3,5 \% \text { taxi/lotação } \\
28,5 \% \text { nenhum (a pé) } \\
100 \% \text { total }\end{array}$ & $\begin{array}{l}50 \% \text { motocicleta } \\
25 \% \text { carro } \\
0 \% \text { bicicleta } \\
12,5 \% \text { coletivo } \\
12,5 \% \text { taxi/lotação } \\
0 \% \text { nenhum (a pé) } \\
100 \% \text { total }\end{array}$ & $\begin{array}{l}8 \% \text { motocicleta } \\
5 \% \text { carro } \\
2 \% \text { bicicleta } \\
80 \% \text { coletivo } \\
5 \% \text { taxi/lotação } \\
0 \% \text { nenhum (a pé) } \\
100 \% \text { total } \\
\end{array}$ \\
\hline $\begin{array}{l}\text { setor da } \\
\text { economia em } \\
\text { que trabalha }\end{array}$ & $\begin{array}{l}\text { 70,3\% serviços } \\
7,4 \% \text { agropecuária } \\
7,4 \% \text { indústria } \\
14,8 \% \text { não trabalham } \\
100 \% \text { total } \\
\end{array}$ & $\begin{array}{l}75 \% \text { serviços } \\
0 \% \text { agropecuária } \\
0 \% \text { indústria } \\
25 \% \text { não trabalham } \\
100 \% \text { total } \\
\end{array}$ & \begin{tabular}{|l|}
$62,5 \%$ serviços \\
$3,3 \%$ agropecuária \\
$6,6 \%$ indústria \\
$30 \%$ não trabalham \\
$100 \%$ total \\
\end{tabular} \\
\hline renda mensal & $\begin{array}{l}\text { 11,5\% até um salário-mínimo } \\
61,5 \% \text { um salário-mínimo } \\
23,07 \% \text { dois salários- } \\
\text { mínimos } \\
\text { 3,8\% três salários-mínimos } \\
\text { 0\% mais de três salários- } \\
\text { mínimos } \\
\text { 100\% total }\end{array}$ & $\begin{array}{l}12,5 \% \text { até um salário-mínimo } \\
50 \% \text { um salário-mínimo } \\
12,5 \% \text { dois salários-mínimos } \\
25 \% \text { três salários-mínimos } \\
0 \% \text { mais de três salários- } \\
\text { mínimos } \\
\text { 100\% total }\end{array}$ & $\begin{array}{l}\text { 30\% até um salário-mínimo } \\
\text { 40\% um salário-mínimo } \\
\text { 26,6\% dois salários-mínimos } \\
\text { 3,3\% três salários-mínimos } \\
\text { 0\% mais de três salários- } \\
\text { mínimos } \\
\text { 100\% total }\end{array}$ \\
\hline
\end{tabular}

fonte: Trabalho de campo, julho de 2018.

elaboração: Mauro Emilio, 2019.

questionário foi aplicado com 30 pessoas em cada centro, perfazendo 90 pessoas consultadas. Assim, os dados forneceram os seguintes resultados socioeconômicos:

11 "As condições de evolução da economia moderna e o enorme peso de uma população urbana com baixo nível de vida, que não pára de aumentar com a chegada maciça de migrantes vindos do campo, acarretam a existência, ao lado do circuito moderno, de um circuito econômico não moderno, que compreende a pequena produção manufatureira, freqüentemente artesanal, o pequeno comércio de uma multiplicidade de serviços de toda espécie" (Santos, 2004, p. 197). 
Nos centros da Nova Marabá (35,7\%) e Cidade Nova (50\%), a motocicleta predominou como meio de transporte, enquanto no centro da Marabá Pioneira (80\%), o principal foi o ônibus coletivo. Isso denota que os frequentadores do centro da Marabá Pioneira têm renda mais baixa, o que se confirmada pela predominância de pesquisados com renda de até um salário-mínimo (30\%), seguido da Cidade Nova (12,5\%) e Nova Marabá (11,5\%). Assim, Marabá Pioneira é o centro mais popular da cidade.

O centro da Cidade Nova figura-se como o mais elitizado quanto ao meio de transporte utilizado por seus frequentadores, uma vez que o carro particular é o transporte de $25 \%$ dos usuários pesquisados; seguido por Nova Marabá $(7,1 \%)$ e, com o baixíssimo índice, por Marabá Pioneira (5\%). Reforçando, assim, a inferência anterior para este último centro (mais popular).

Outra constatação que veio corroborar a literatura sobre mercado de trabalho em Marabá foi a prevalência dos empregos formais no setor terciário de serviços, com índices muito altos em relação aos outros setores: na Cidade Nova (75\%), Nova Marabá (70,3\%) e Marabá Pioneira (62,5\%).

\section{Considerações finais}

A cidade de Marabá é um exemplo da complexa urbanização da Amazônia nos últimos quarenta anos, isto é, uma cidade onde coexistem dialeticamente elementos do novo e do antigo.

Oenfoque intraurbano se dedicou aos três centros da cidade de Marabá, que há tempos foi monocêntrica e, com a expansão urbana ordenada e desordenada, teve seu tecido urbano complexificado ao surgirem e/ou se ampliarem suas dinâmicas espaciais de centro(s) e centralidade(s).

A Marabá Pioneira tem aspecto de centro tradicional e principal, com forte tendência a um comércio popular, além de seu ethos de núcleo de formação do território marabaense. A Nova Marabá implica uma perspectiva de planejamento nos moldes supralocais não completado, mas tem uma importância significativa para a instalação do aparelho governamental, com sua função política, e abriga os terminais rodoviários e hotéis de vários padrões, além dos fluxos decorrentes das instituições universitárias e de seu objeto mais moderno no âmbito escalar, o shopping center Pátio.

Por fim, a Cidade Nova, constituída como parte dos desdobramentos de processos das duas primeiras, é um mosaico de contradições socioespaciais e um cerne com vida diurna e imediata com vida noturna, ao mesmo tempo em que também se caracteriza como suporte institucional e vetor escalar da cidade, abrigando entidades federais como o Incra e o aeroporto.

Assim, pode-se afirmar que há, entre os três centros, uma divisão territorial urbana do trabalho, com demandas socioeconômicas para todos, e, no âmbito da Geografia Urbana, uma complementariedade superior à competitividade.

Na perspectiva da Geografia Urbana Crítica, o processo de reestruturação urbana da cidade em Marabá, verificado na acentuação das atividades de serviços e comércio que impulsionam o centro e a centralidade, põe em evidência o "espaço-mercadoria" (Carlos, 2001), que tende a solapar as relações do movimento do uso sob o signo do capital com predomínio da 
troca, que aliena o homem na esfera do consumo e do arranjo espacial, conferindo ao centro a antitética relação do trinômio homem-capital-meio.

\section{Referências}

AB'SABER, A. N. Geomorfologia do sítio urbano de São Paulo. Boletim da Faculdade de Filosofia, Ciências e Letras da USP, São Paulo, n. 219, 1957.

BECKER, B. Amazônia. São Paulo: Ática, 1990.

CAMAGNI, R. Economia urbana. Barcelona: Antônio Bosch, 2005.

CARLOS, A. F. A. Espaço-tempo na metrópole: a fragmentação da vida cotidiana. São Paulo: Contexto, 2001.

CORRÊA, R. L. O espaço urbano. São Paulo: Ática, 1989.

GOTTDIENER, M. A produção social do espaço urbano. 2a ed. São Paulo: Edusp, 2010. IBGE. INSTITUTO BRASILEIRO DE GEOGRAFIA E ESTATÍSTICA. Censo 2010. Rio de Janeiro. Disponível em: https://censo2010.ibge.gov.br/. Acesso em: 7 jul. 2020.

LEFEBVRE, H. A revolução urbana. Trad. Sergio Martins. Belo Horizonte: Ed. UFMG, 1999.

LEFEBVRE, H. A vida cotidiana no mundo moderno. Trad. Alcides João de Barros. São Paulo: Ática, 1991.

LENCIONE, S. Cidade-região. In: SPOSITO, E. S. Glossário de geografia humana e econômica. São Paulo: Ed. Unesp, 2017. p. 57-63.

MARABÁ. SEPLAN. Secretaria de Planejamento e Controle. Revisão do Plano Diretor 2017. Disponível em: http://www.maraba.pa.gov.br. Acesso em: 7 jul. 2020.

MARX, K. O capital: crítica da economia política. Trad. Regis Barbosa e Flávio R. Kothe. São Paulo: Nova Cultural, 1996. v. 1.

MASSEY, D. Pelo espaço: uma nova política da espacialidade. Trad. Rogério Haesbaert da Costa. Rio de Janeiro: Bertrand Brasil, 2008.

MIYAZAKI, V. K. Aglomeração urbana. In: SPOSITO, E. S. Glossário de Geografia Humana e Econômica. São Paulo: Ed. Unesp, 2017. p. 9-21.

MONTENEGRO, M. R. O circuito inferior da economia urbana na cidade de

São Paulo no período da globalização. Dissertação (Mestrado em Geografia) Faculdade de Filosofia, Letras e Ciências Humanas, Universidade de São Paulo, São Paulo, 2006.

SAlGUEIRO, T. B. Do centro às centralidades múltiplas. In: FERNANDES, J. A. V. R.; SPÓSITO, M. E. B. A nova vida do velho centro nas cidades portuguesas e brasileiras. Porto, PT: Faculdade de Letras da Universidade do Porto/Cegot, 2012.

SANTOS, M. O centro da cidade do Salvador: estudo de geografia urbana. 2a ed. São Paulo: Edusp, 2012. 
SANTOS, M. A natureza do espaço: técnica e tempo, razão e emoção. 4a ed. São Paulo: Edusp, 2008.

SANTOS, M. O espaço dividido. 6a ed. São Paulo: Edusp, 2004.

SANTOS, M.; SILVEIRA, M. L. O Brasil: território e sociedade no início do século XXI. 18a ed. Rio de Janeiro: Record, 2014.

SMITH, N. Desenvolvimento desigual. Rio de Janeiro: Bertrand Brasil, 1988.

SOUZA, M. L. Os conceitos fundamentais da pesquisa socioespacial. Rio de Janeiro: Bertrand Brasil, 2013.

SPÓSITO, M. E. B. Configurações espaciais urbanas. In: SPOSITO, E. S. Glossário de Geografia Humana e Econômica. São Paulo: Ed. Unesp, 2017. p. 25-31.

SPÓSITO, M. E. B. Capitalismo e urbanização. 15a ed. São Paulo: Contexto, 2008.

SPÓSITO, M. E. B. A gestão do território e as diferentes escalas da centralidade urbana. In: ENCONTRO NACIONAL DA ANPEGE, 2., 1997, Rio de Janeiro. Anais... Rio de Janeiro, 1997.

TEODÓSIO, A. S. S. Escola de Chicago: heranças para o pensamento social contemporâneo sobre as cidades. In: CONGRESSO BRASILEIRO DE SOCIOLOGIA, 11., 2003, Campinas. Anais... Campinas, SP: Unicamp, 2003.

TOURINHO, H. L. Z. Estrutura urbana de cidades médias amazônicas: análise considerando a articulação das escalas interurbana e intraurbana. Tese (Doutorado em Desenvolvimento Urbano) - Universidade Federal de Pernambuco, Recife, 2011.

VILLAÇA, F. Espaço intra-urbano no Brasil. 2a ed. São Paulo: Fapesp, 2001.

WHITACKER, A. M.; MIYAZAKI, V. O estudo das formas da cidade no âmbito da geografia urbana: apontamentos metodológicos. Revista de Geografia e Ordenamento do Território, n. 2, p. 307-327, 2012. doi: http://dx.doi.org/10.17127/got/2012.2.013.

YOSCHIOKA, H. Avaliação de implantação de um núcleo urbano em área na Amazônia: o exemplo de Nova Marabá, Pará. Dissertação (Mestrado em Geografia) Faculdade de Filosofia, Letras e Ciências Humanas, Universidade de São Paulo, São Paulo, 1986. 